materials, medical physics, etc.) which could be brought together with EPS into an European Institute of Physics. Channels to collaborate with societies in other disciplines (chemistry, biology, etc.) should also be found.

Regarding publications, Europhysics Letters, whose scientific well-being is an EPS responsibility, remains a success both financially and in terms of how it meets the professional needs of the physics community. The next key issue is electronic publishing. We have started to consider how the journal could find a major presence in this increasingly important environment.

Norbert Króo, the President of EPS, is the Director of the Research Institute for Solid State Physics of the Hungarian Academy of Sciences. His two-year term of office ends immediately following the annual meeting of the Council of EPS (Bad Honnef; 24-25 March 1995). He will be proposed to Council as the Vice-President since his term of office on the Executive Committee lasts for another year. Herwig Schopper from CERN, who was elected as the President-Elect for one year at the 1994 Council in Cracow, will be proposed to Council in Bad Honnef as the next President.

\section{SOLIDARITY FUND}

\section{Applications Sought}

An EPS Solidarity Fund was set up last year to help provide some starting capital to organizers of new conferences, workshops and schools, and to fund grants to help participation at EPS conferences by young people and scientists from economically weak regions. The aim is to transfer to the Fund $20 \%$ of a SFR 20.- levy made on each participant at an EPS conference (the remaining $80 \%$ would be earmarked for use by the Division or Interdivisional Group that organized the conference).

Some SFR 10000.- that was set aside in last year's budget for Division and Group activities but was not taken up has been transferred to the Fund. Moreover, the High-Energy and Particle Physics Division has made a voluntary contribution of SFR 5000.-. So meetings' organizers and conference participants coming from the economically weaker parts of Europe are encouraged to submit applications. This can be done by contacting the Chair of your Division or Group who will forward your application to the Secretary of the Conference Committee which manages the Fund. The names and addresses of Chairs are listed in the EPS Directory published in the July 1994 of Europhysics News and available on World-Wide Web at http://192.16. 199.1/www/pub/eps/eps.html.
The European Journal of Physics, which is published in partnership with The Institute of Physics (UK) and specializes in physics teaching, is operating extremely well. I have to pay tribute to George Series, the first Editor, who died recently and express my happiness that Lennart Samuelssen, the previous chairman of the Education Committee, took over in January from A.B. Pippard as the Editor.

\section{Redefined Goals}

Europe is changing very rapidly. We in physics must react more quickly in finding the optimum path. We expect this first of all from ourselves. But I am convinced that the outside world expects it as well. We have to hand over to future generations a Society capable of contiunously regenerating itself so that it can host and breed the good ideas that will strengthen European physics, and in so doing foster an increasingly integrated continent.

I therefore consider the structural changes, and the increased emphasis on some of our activities, as important steps towards a more efficient and widely respected Society in the fully integrated Europe which I believe will emerge one day. For we can

\section{EPCS Board Elections}

Members of the EPS Interdivisional Group for Experimental Physics Control Systems (EPCS) are invited to nominate candidates for the election of four Board Members to take office on 1 July 1995. Members normally serve for three years, with the option of reelection for another three years. The Board presently comprises:

Chair: A. Daneels (CERN, Geneva)

Vice-Chair: W. Busse (HMI, Berlin)

Treasurer: T. Blumer (PSI, Villigen)

Members: P. Clout (VISTA Control

Systems: IEEE contact)

M. Clausen (DESY, Hamburg)

L. Trasatti (INFN-LNF, Frascati)

T. Katoh (KEK, Tsukuba).

W. Busse, T. Blumer, P. Clout and A. Daneels have come to the end of their six-year terms of office so they will have to be replaced.

For a nomination to be valid the nominee must be a member of EPCS and the nomination form should to be signed by three EPCS members, be accompanied by a statement of consent from the nominee, and be received by 15 March 1995. Nominations should be sent to W. Busse, Hahn-Meitner-Institut, Glienicker Str. 100, D-14109 Berlin. Nomination forms can be requested from $\mathrm{W}$. Busse by fax ( $+4930-80622097$ ) or e-mail (busse (@) vax.hmi.d400.de).

The EPS Interdivisional Group for Experimental Physics Control Systems (EPCS) is the platform for control specialists from several companies and more than 40 physics facilities world-wide. Know-how flows freely via privileged communication channel so ideas, opinions and problems can be discussed in an open, friendly environment. Smaller com- only compete with other regions in the world if we exploit all of our intellectual resources, whether they be from east or west, north or south.

New goals have to be defined following the collapse of the Iron Curtain since the Society's bridge-building role between east and west has already lost much of its meaning. The main task now is integration and here physics, as in the bridge building of former years, can again make a major contribution. We should not give this up as one of our ambitions.

Young scientists - their interest in research, their access to jobs and their involvement in a broader range of issues than their own scientific work - should also be one of our central concerns. We have to help them find ways and means to be able to expand their horizons.

But in redefining our objectives we should, of course, not forget our traditional activities such as the organization of workshops, conferences and schools, publishing, the safe-guarding of scientific and intellectual freedom, and efforts to articulate the opinion of the physics community on important scientific issues.

N. Króo, Budapest

panies and laboratories are also able to have a say in a domain that in the past appeared more the business of large organizations.

EPCS contributes significantly to promoting closer collaboration between laboratories and with industry, which in turn uses the Group to evaluate and disseminate products and to promote their development. The outcome is a rather homogeneous marketplace in which favourable terms for purchasing products are often established.

Individual Ordinary Members and National Society Members of EPS are encouraged to join EPCS if they would like to contribute to the Group's work. As for all EPS Divisions and Groups, there is no membership fee.

\section{Agreement on General Conference}

The Board of the EPS Condensed Matter Division (CMD) has reached agreement with the French Physical Society, the Condensed Matter and Materials Physics Division of the Institute of Physics (UK) and the Solid-State Physics Division of the German Physical Society to hold the CMD General Conference jointly every three years together with the Divisional meeting of one of the three national societies. In the intervening years, the CMD conference will hopefully tend to be held in smaller countries, perhaps also in collaboration with national societies. The first joint event will be held with the French Physical Society's Journées de Matière Condensée in 1998. The agreement follows much discussion on the future of the CMD conference and the need to hold conferences in smaller countries while ensuring that all condensed matter physicists attend. 